\title{
Fixed-bearing vs mobile-bearing prostheses for total knee arthroplasty after approximately 10 years of follow-up: a meta-analysis
}

Dongsheng $\mathrm{HaO}^{1 * \dagger}$ and Junjie Wang ${ }^{2+}$

\begin{abstract}
Background: The benefits and risks of fixed-bearing and mobile-bearing designs for total knee arthroplasty (TKA) were compared, and long-term functional, clinical and radiological outcomes were analysed.

Methods: A comprehensive search in the PubMed, EMBASE, Web of Science and Cochrane Central databases was conducted to identify randomized controlled trials (RCTs) comparing fixed-bearing and mobile-bearing designs with no less than 9 years of follow-up. Primary outcome measures were Knee Society Scores (KSSs), range of motion (ROM) in knee joint values, complication rates and revision rates. The final search was performed on 23 April 2021.

Results: Six RCTs were included. A total of 451 patients with 612 knees met the inclusion criteria. The mobilebearing design, in contrast to the fixed-bearing design, can clearly increase the KSFSs, especially with posterior cruciate retention. There was no significant difference in the KSKSs, ROM values, revision rates or complication rates between the two bearing design groups.

Conclusion: After approximately 10 years of follow-up, the mobile-bearing design has advantages in KSFSs over the fixed-bearing design. The mobile-bearing design may also have advantages in the revision rates over the fixedbearing design when the posterior cruciate ligament is substituted. There may be no clear difference in KSKSs, ROM values or complication rates between these two designs.
\end{abstract}

Keywords: Fixed-bearing, Mobile-bearing, Total knee arthroplasty, Meta-analysis, Randomized controlled trials

\section{Introduction}

Joint diseases such as osteoarthritis (OA) and rheumatoid arthritis (RA) in the knees can lead to topical pain, loss of joint function and a poor quality of life. If the damage and pain in the knee due to arthritis are too severe, joint replacement surgery is required. Total knee arthroplasty (TKA) is a reliable and prevalent end-stage

\footnotetext{
* Correspondence: 13426364680@163.com

${ }^{\dagger}$ Dongsheng Hao and Junjie Wang contributed equally to this work. 'Shanxi Bethune Hospital, Shanxi Academy of Medical Science, No. 99, Longcheng Street, Taiyuan 030032, Shanxi Province, China Full list of author information is available at the end of the article
}

arthritis orthopaedic operation that can reduce pain and enhance the physical function of the knee. With the occurrence of knee OA and RA continuing to increase, it is expected that the number of TKAs will increase exponentially in the future $[1,2]$. However, long-term followup data have revealed risks for loosening and wear of the implants often leading to revision surgery. Approximately $10 \%$ of TKAs require revision surgery and loosening and wear account for approximately $21 \%$ of all revisions $[3,4]$. Loosening is related to stresses at the bone fixation site, whereas wear is mainly due to a lack of congruency during implant motion [5]. To prolong

C C The Author(s). 2021 Open Access This article is licensed under a Creative Commons Attribution 4.0 International License, which permits use, sharing, adaptation, distribution and reproduction in any medium or format, as long as you give appropriate credit to the original author(s) and the source, provide a link to the Creative Commons licence, and indicate if changes were made. The images or other third party material in this article are included in the article's Creative Commons licence, unless indicated otherwise in a credit line to the material. If material is not included in the article's Creative Commons licence and your intended use is not permitted by statutory regulation or exceeds the permitted use, you will need to obtain permission directly from the copyright holder. To view a copy of this licence, visit http://creativecommons.org/licenses/by/4.0/ The Creative Commons Public Domain Dedication waiver (http://creativecommons.org/publicdomain/zero/1.0/) applies to the data made available in this article, unless otherwise stated in a credit line to the data. 


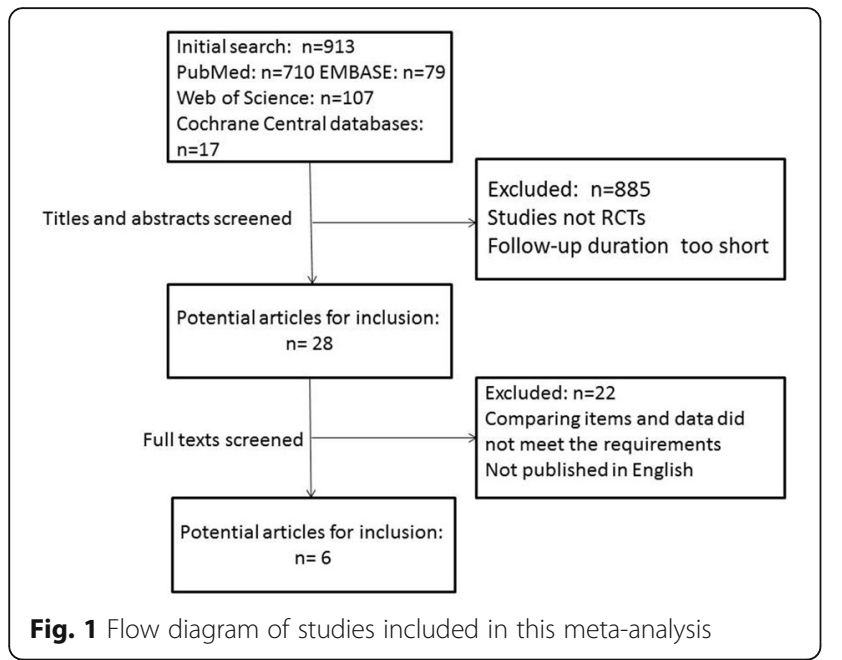

the lifespan of implants, TKA has undergone a rapid technological development phase in recent years. The results of this technological development have been applied in clinical practice and more recent TKA designs have sought to increase the congruency without increasing the stress on the implant fixation site [6], thus reducing the risk for loosening and wear.

Fixed-bearing and mobile-bearing are two kinds of bearing designs for TKA. A fixed-bearing knee design has round femoral components that articulate with a relatively flat tibial articular surface. Although this configuration allows for some axial rotation, it results in high contact stress between the femoral and tibial surface. Because of these circumstances, the concept of a mobile-bearing knee design was developed. Due to its motion at the tibia-insert interface, greater tibiofemoral congruency can be achieved, reducing wear on the implants and reproducing more natural kinematics of the knee; these processes are not accompanied by an increase in the stress at the boneimplant interface [7], resulting in increased durability and knee function. Laboratory testing and computer modelling have confirmed that mobile-bearing designs helps to minimize wear by reducing delamination and fatigue fractures in theory [8]. However, the study also suggested that the additional surface wear could offset the reduction in wear at the femorotibial articulation site [9]. To compare the benefits and harms of fixed-bearing versus mobile-bearing TKAs, numerous comparative studies have been conducted in the past two decades, and most studies concluded that there is no difference between fixed-bearing and mobilebearing designs with regard to pain, range of motion (ROM) or function [10, 11]. A previous meta-analysis also concluded that mobile-bearing designs had similar effects on knee pain, clinical and functional scores, health-related quality of life scores, revision surgery rates, mortality rates, reoperation rates and other serious adverse events compared with fixed-bearing designs. However, they included only studies that evaluated posterior cruciate-retaining TKA, and the follow-up duration of their included studies was not long enough [12]. It is widely accepted that posterior cruciate-retaining TKA can maintain stability from extension to flexion, while posterior cruciatesubstituting TKA can increase the flexion and extension gaps $[13,14]$. Considering that cruciate retaining

Table 1 Characteristics of the included studies

\begin{tabular}{|c|c|c|c|c|c|c|}
\hline First author & Young-Hoo Kim & Steven T. Woolson & B. G. Pijls & N. Poirier & M. P. Abdel & A. J. Powell \\
\hline Publication year & 2009 & 2011 & 2012 & 2015 & 2018 & 2018 \\
\hline Country & South Korea & USA & Netherlands & France & USA & New Zealand \\
\hline $\begin{array}{l}\text { Number of patients in } \\
\text { fixed/mobile group }\end{array}$ & $61 / 61$ & $26 / 23$ & 33 & $31 / 30$ & $61 / 53$ & 72 \\
\hline $\begin{array}{l}\text { Number of male patients } \\
\text { in fixed/mobile group }\end{array}$ & 16 & - & $5 / 3$ & $13 / 14$ & - & - \\
\hline $\begin{array}{l}\text { Number of knees in fixed/ } \\
\text { mobile group }\end{array}$ & $122 / 122$ & $30 / 31$ & $21 / 21$ & $31 / 30$ & $66 / 53$ & $46 / 39$ \\
\hline $\begin{array}{l}\text { Mean age in fixed/mobile } \\
\text { group }\end{array}$ & 48.3 (range 34-55) & $\begin{array}{l}77.9 \text { (range 56-96)/ } \\
78 \text { (range 48-91) }\end{array}$ & 66 (SD 14)/64 (SD 11) & $\begin{array}{l}72(\mathrm{SD} 6) / \\
70(\mathrm{SD} 6)\end{array}$ & - & - \\
\hline $\begin{array}{l}\text { Mean BMI in fixed/mobile } \\
\text { group }\end{array}$ & - & $29.2 / 27.7$ & 27 (SD 5.4)/27 (SD 3.1) & - & - & - \\
\hline $\begin{array}{l}\text { Posterior cruciate-retaining } \\
\text { or not }\end{array}$ & Yes & No & No & No & No & Yes \\
\hline $\begin{array}{l}\text { Manufacturer of implants } \\
\text { in fixed/mobile group }\end{array}$ & DePuy/DePuy & Zimmer/DePuy & $\begin{array}{l}\text { Stryker-Howmedica/ } \\
\text { Stryker-Howmedica }\end{array}$ & $\begin{array}{l}\text { Zimmer/ } \\
\text { Zimmer }\end{array}$ & $\begin{array}{l}\text { DePuy Synthes/ } \\
\text { DePuy Synthes }\end{array}$ & $\begin{array}{l}\text { DePuy Synthes/ } \\
\text { DePuy Synthes }\end{array}$ \\
\hline Follow-up duration & $\begin{array}{l}\text { Mean } 10.8 \text { years } \\
\text { (range, } 10-12 \text { years) }\end{array}$ & $\begin{array}{l}10 \text { years (range } 116- \\
160 \text { months) }\end{array}$ & 10 to 12 years & $\begin{array}{l}9 \text { years (SD } \\
1.3)\end{array}$ & $\begin{array}{l}\text { Median } 10 \text { years } \\
\text { (IQR } 9.2 \text { to } 10.4)\end{array}$ & 10 years \\
\hline
\end{tabular}

$\mathrm{SD}$, standard deviation; IQR, interquartile range; $\mathrm{BMI}$, body mass index 


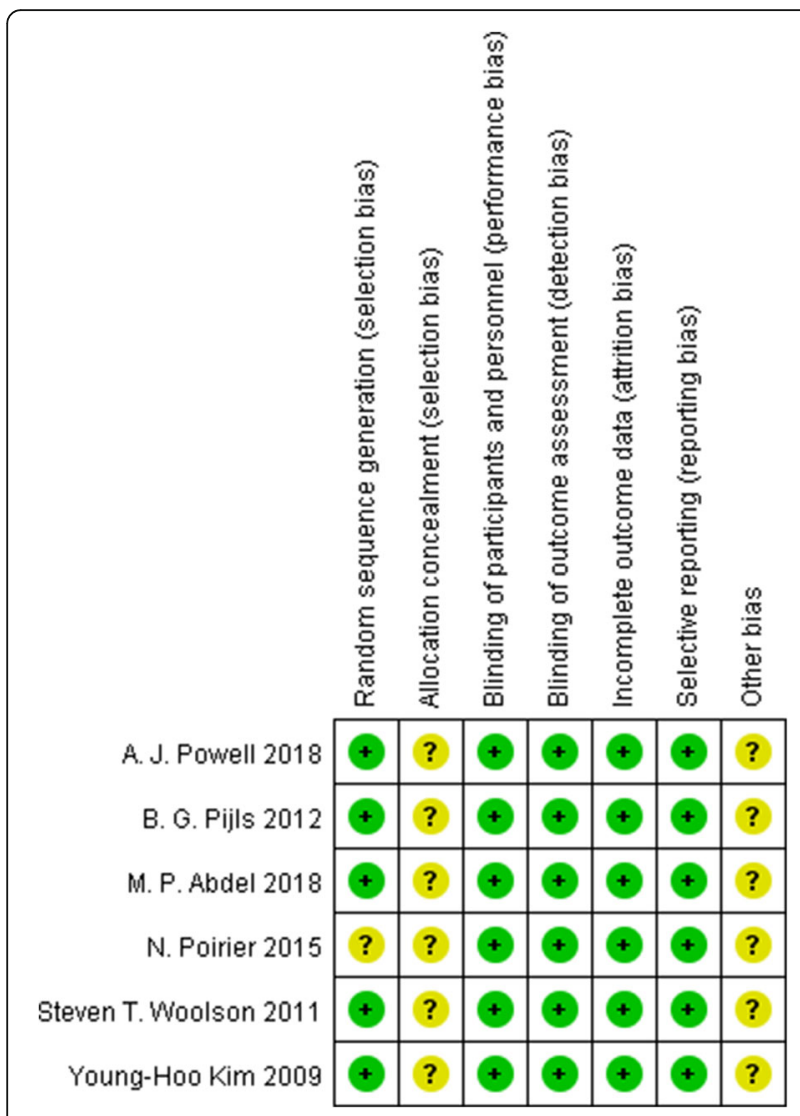

Fig. 2 Quality of the included studies

can influence knee function, it is necessary to perform a meta-analysis that includes long-term followup results and posterior cruciate-substituting TKAs.

This article compares the benefits and harms of fixedbearing and mobile-bearing TKAs for some long-term functional, clinical and radiological outcomes with a meta-analysis of randomized controlled trials (RCTs).

\section{Materials and methods}

\section{Search strategy}

Two trained researchers independently searched major online databases, including PubMed, EMBASE, the Web of Science and the Cochrane Central Register of Controlled Trials, on 23 April 2021. Different combinations of the following terms were used to perform the search: "total knee arthroplasty", "total knee replacement", "knee arthroplasty", "knee replacement", "total knee", "mobile bearing", "fixed bearing" and "rotating platform".

\section{Study identification and eligibility criteria}

The two researchers independently screened the titles and abstracts in the online databases and excluded ineligible studies. Subsequently, they read the full texts to include eligible studies that met the following criteria: (1) the participants were individuals who suffered from severe knee diseases; (2) the intervention included TKA surgery that compared fixed-bearing and mobile-bearing designs; (3) the anticipated outcomes included values that evaluate knee function, knee joint ROM, revision rates or other associated values; (4) the follow-up duration was at least 9 years on average; (5) the type of study was an RCT; and (6) the full text was published in English.

\section{Data extraction and assessment of risk of bias}

Two researchers screened the included studies and extracted the following information: first author name, publication year, study population country, number of participants allocated to each group, number of male participants in each group, number of knees in each group, number of diabetic patients, number of alcohol abusers, number of smokers, number of immunosuppressed individuals, mean age of each group, mean body mass density (BMI) of each group, type of TKA (posterior cruciateretaining or not), implant manufacturer of each group and follow-up duration of each group. Disagreements were resolved with the help of a third investigator. The Cochrane risk of bias tool was used to evaluate the methodological quality of the studies [15].

\section{Statistical analysis}

The two investigators identified and recorded the following outcomes: Knee Society Scores (KSSs), ROM, complication rates and revision rates. The KSSs include the KSKSs, which are mainly used to evaluate pain, ROM, and knee stability, and the KSFSs, which are used to evaluate a patient's ability to walk and climb stairs [16].

The meta-analysis was performed using RevMan 5.3. Odds ratios (ORs) and 95\% confidence intervals (CIs) were calculated for the dichotomous variables, and a

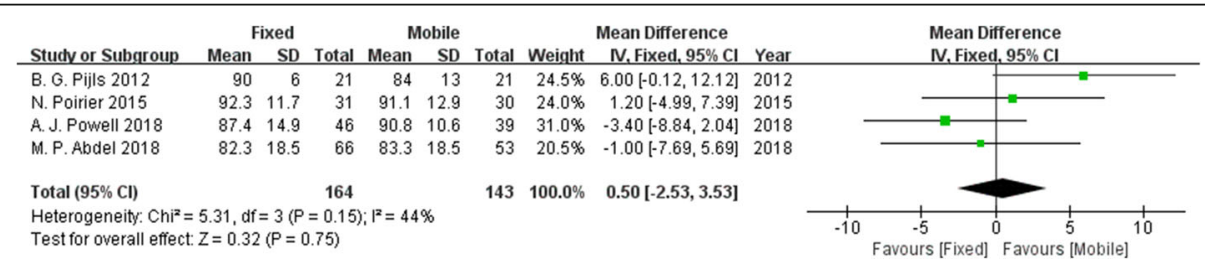

Fig. 3 Forest plot for KSKSs. There was no clear difference in the KSKSs between the fixed-bearing design and mobile-bearing design 


\begin{tabular}{|c|c|c|c|c|c|c|c|c|c|c|c|c|c|}
\hline Study or Subgroup & \multicolumn{3}{|c|}{ Fixed } & \multicolumn{3}{|c|}{ Mobile } & \multicolumn{3}{|c|}{ Mean Difference } & \multicolumn{4}{|c|}{$\begin{array}{l}\text { Mean Difference } \\
\text { IV. Fixed, } 95 \% \mathrm{Cl}\end{array}$} \\
\hline B. G. Pijls 2012 & 63 & 33 & 21 & 63 & 28 & 21 & $8.0 \%$ & $0.00[-18.51,18.51]$ & 2012 & & & & \\
\hline N. Poirier 2015 & 77.1 & 24.1 & 31 & 86.8 & 18.3 & 30 & $23.9 \%$ & $-9.70[-20.42,1.02]$ & 2015 & & & & \\
\hline A. J. Powell 2018 & 75.1 & 20.3 & 46 & 86.2 & 18.7 & 39 & $39.9 \%$ & $-11.10[-19.40,-2.80]$ & 2018 & $\rightarrow$ & & & \\
\hline M. P. Abdel 2018 & 56.7 & 16.9 & 66 & 60 & 33.4 & 53 & $28.2 \%$ & $-3.30[-13.17,6.57]$ & 2018 & & & & \\
\hline Total $(95 \% \mathrm{Cl})$ & & & 164 & & & 143 & $100.0 \%$ & $-7.68[-12.92,-2.44]$ & & & & & \\
\hline $\begin{array}{l}\text { Heterogeneity. } \mathrm{Chi}^{2}= \\
\text { Test for overall effect }\end{array}$ & $\begin{array}{l}2.21, d \mathrm{~d} \\
Z=2.8\end{array}$ & $\begin{array}{l}=3(P \\
(P=0\end{array}$ & $\begin{array}{l}=0.53) \\
0.004)\end{array}$ & $F^{2}=09$ & & & & & & $\begin{array}{c}10 \\
\text { Favours [Fixed] }\end{array}$ & i] Favours & $\begin{array}{l}10 \\
\text { [Mobile] }\end{array}$ & 20 \\
\hline
\end{tabular}

Fig. 4 Forest plot for KSFSs. The mobile-bearing design, in contrast to the fixed-bearing design, can significantly increase KSFSs.

random-effects model was used. The mean difference (MD) and 95\% CIs were calculated for continuous variables, and a fixed-effects model was used. Statistical significance was deemed to exist when $P<0.05$. The heterogeneity across studies in comparisons was identified using the chi-square $\left(x^{2}\right)$ and $\mathrm{I}^{2}$ tests; if $P<0.05$ and $\mathrm{I}^{2}>50 \%$, heterogeneity was considered to exist. For continuous variables, if $P<0.05$ and $\mathrm{I}^{2}>50 \%$, a randomeffects model was applied.

\section{Results}

\section{Literature search}

In total, 913 studies were screened using our search method after duplicates were removed. Subsequently, 885 titles were not eligible for inclusion after the titles and abstracts were read, and 28 trials remained that required a full-text review. Afterwards, 22 articles were eliminated because their full texts were either not published in English or the comparison items did not meet our requirements. Finally, 6 articles were eligible for this meta-analysis [17-22] (Fig. 1).

\section{Study characteristics}

Table 1 provides detailed baseline data for the 6 included studies. The publication year ranged from 2009 to 2018. The sample size of each group ranged from 33 to 122 patients. In total, 451 patients with 612 knees were included. Two studies involved posterior cruciateretaining TKA, and most studies, with one exception, utilized implants that were manufactured by the same company in both groups [21]. The mean follow-up duration ranged from 9 years to 12 years. None of the included studies reported that they enrolled diabetic patients, alcohol abusers, smokers or immunosuppressed patients.

\section{Study quality}

The methodological quality of all RCTs included was deemed to be relatively high (Fig. 2), with most aspects evaluated as having a low risk of bias.

According to Egger et al. [23], using the symmetry of a funnel plot to assess publication bias is not a precise method for a meta-analysis that includes 10 or fewer studies. Therefore, a funnel plot was not presented in this meta-analysis.

\section{Knee Society Knee Scores (KSKSs)}

After screening the 6 studies, we found that KSKSs were reported by more than one study. Figure 3 indicates no clear difference in the KSKSs between the fixed-bearing design and mobile-bearing design.

\section{Knee Society Function Scores (KSFSs)}

KSFSs were reported in four studies. Figure 4 shows that the mobile-bearing design, in contrast to the fixedbearing design, can significantly increase KSFSs.

\section{ROM}

Detailed information on ROM was provided in two studies. Figure 5 demonstrates that there was no significant difference between the fixed-bearing and mobile-bearing design for ROM.

\section{Revision rates}

Six studies investigated the revision rates. Figure 6 suggests that no difference in the revision rates was found between the fixed-bearing and mobile-bearing designs.

\section{Complication rates}

Four complications were reported by more than one study and were included in our meta-analysis: aseptic loosening, deep infection, radiolucent lines and

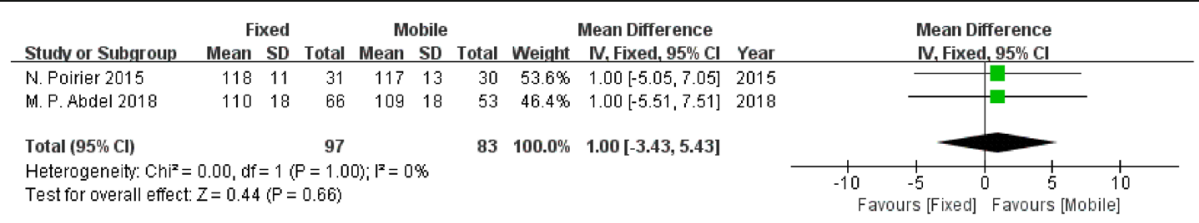

Fig. 5 Forest plot for ROM. There was no significant difference between the fixed-bearing and mobile-bearing design for ROM. 


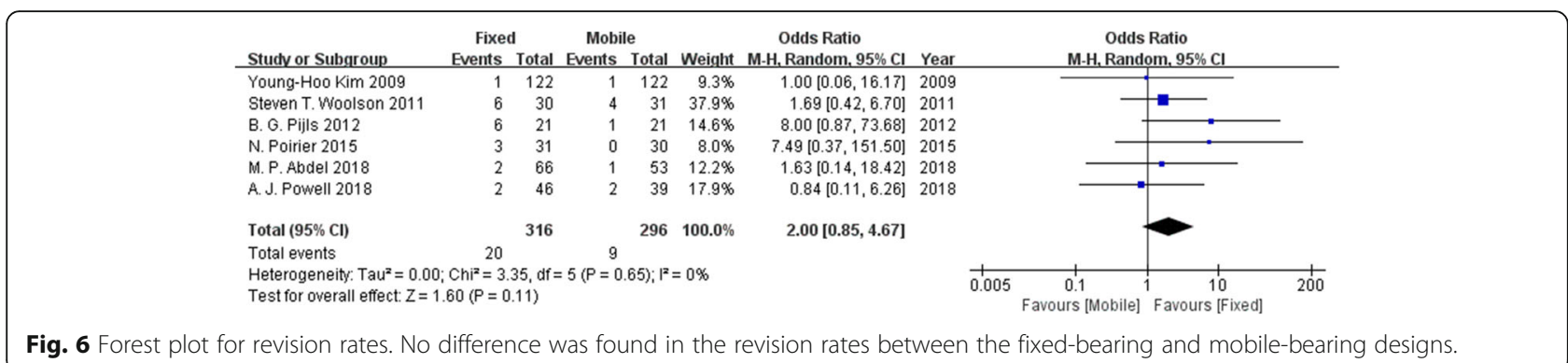

osteolysis. Table 2 presents the results of the pooled statistical analysis and shows that there was no difference in complication rates between the fixed-bearing and mobile-bearing designs.

\section{Subgroup analyses}

To investigate the influence of posterior cruciateretaining TKA, we conducted subgroup analyses of comparisons with sufficient sample sizes. We established the subgroups based on whether the posterior cruciate ligament was retained. The KSKSs, KSFSs, revision rates, aseptic loosening, deep infection and osteolysis were analysed. Figure 7 shows no clear difference in the KSKSs regardless of whether the posterior cruciate ligament was retained. Figure 8 indicates that compared with the fixed-bearing design, the KSFSs was increased in the mobile-bearing design with posterior cruciate retention, while no significant difference in the KSFSs was found between the two bearing designs without posterior cruciate retention. Figures 9, 10, 11, and 12 show no clear difference in the revision rates, aseptic loosening or deep infection between the fixed-bearing and mobilebearing designs, regardless of whether the posterior cruciate ligament was retained.

\section{Discussion}

Overall, the forest plot results suggest that the mobilebearing design, in contrast to the fixed-bearing design, can clearly increase the KSFSs, especially with posterior cruciate retention. There was no significant difference in the KSKSs, ROM values, revision rates or complication rates between the two bearing design groups.

Two types of outcomes were used to compare fixedbearing and mobile-bearing designs. The KSSs and
ROM can be used to assess knee function, while the revision rates and complication rates can be used to evaluate the lifespan of the implants. Our meta-analysis indicated that after approximately 10 years of follow-up, the KSFSs were much higher in the mobile-bearing design group than in the fixed-bearing design group, whereas the difference in KSKSs was not clear between the two designs. This result is quite different from a previous meta-analysis that indicated no significant difference in the KSKSs or KSFSs between the two bearing designs [12]. A possible reason for this discrepancy may be that our follow-up duration was consistently long while the follow-up duration in their study was mixed. In our subgroup analyses, the mobile-bearing design with posterior cruciate retention was associated with an increase in the KSKSs, and the fixed-bearing design with posterior cruciate substitution was associated with an increase in the KSKSs. However, these results may not be considered conclusive because only one study was included in the posterior cruciate retention subgroup, and the $\mathrm{p}$ value was not greater than 0.05 . Perhaps the small sample size influenced our results. The forest plot showed that the KSFSs were similar between the two subgroups and consistent with the original results. A previous meta-analysis concluded that there were no clinically relevant differences between posterior cruciateretaining TKA and posterior cruciate-stabilizing TKA in terms of clinical and functional outcomes [24], but their follow-up duration was too short, and the KSSs may have changed over time. Further studies are needed to explore the effect of retention of the posterior cruciate ligament. In addition to the KSSs, ROM can be used to evaluate the knee joint. Our meta-analysis suggests that after approximately 10 years, the fixed-bearing and

Table 2 The results of the forest plots for complication rates

\begin{tabular}{|c|c|c|c|c|c|c|c|c|}
\hline Complication & Number of patients & Number of included studies & OR & $95 \% \mathrm{Cl}$ & $P$ value & $x^{2}$ & $I^{2}$ & Effect model \\
\hline Aseptic loosening & 246 & 3 & 2.72 & $0.42,17.58$ & 0.29 & 0.99 & $0 \%$ & Random effects \\
\hline Deep infection & 490 & 4 & 0.58 & $0.14,2.39$ & 0.45 & 0.67 & $0 \%$ & Random effects \\
\hline Radiolucent line & 329 & 2 & 2.10 & $0.51,8.69$ & 0.30 & 0.24 & $28 \%$ & Random effects \\
\hline Osteolysis & 366 & 3 & 1.87 & $0.21,16.65$ & 0.58 & 0.08 & $61 \%$ & Random effects \\
\hline
\end{tabular}




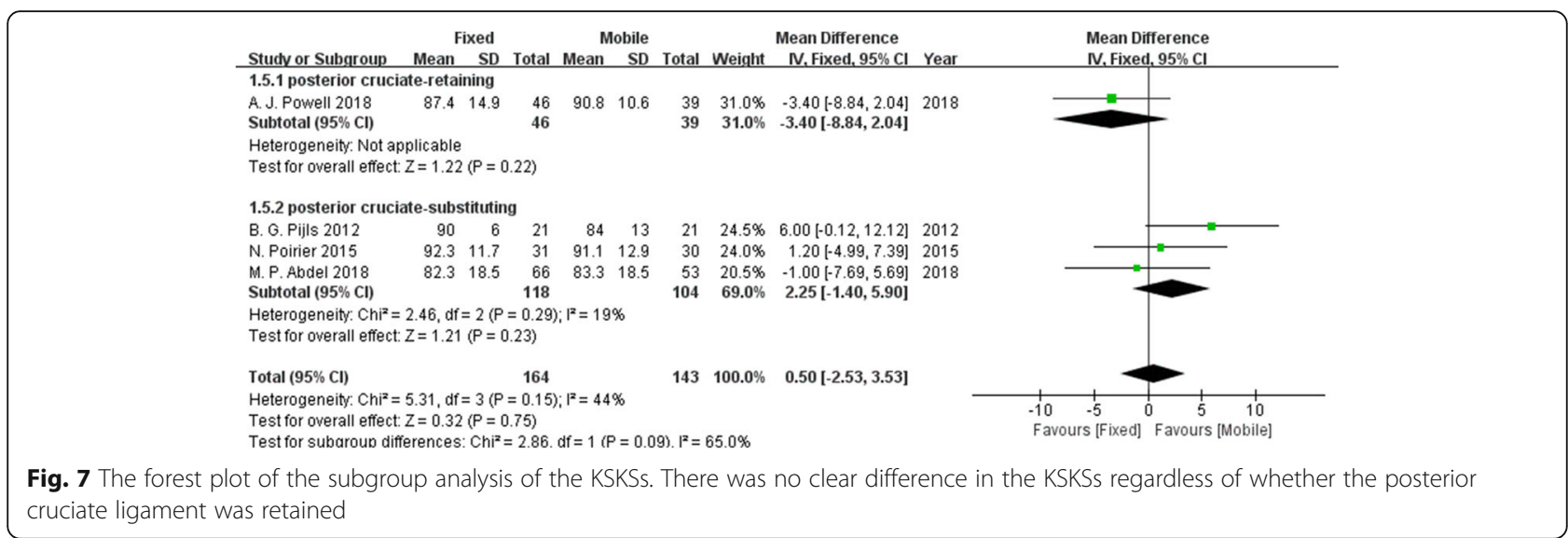

mobile-bearing designs have nearly identical ROM values, which is consistent with our KSKS results. Further studies are needed to explore the effect of posterior cruciate ligament retention on ROM.

The original aim of the mobile-bearing design was to reduce wear, prolong the lifespan of the implant and reduce the revision rates. Common reasons for revision include aseptic loosening, deep infection, fracture, radiolucent lines, osteolysis, wear and dislocation [3]. Our meta-analysis suggested that the risks for radiolucent lines, osteolysis, aseptic loosening and deep infection were similar for the two bearing designs. In addition, our meta-analysis indicated that there was no clear difference in the revision rates between the two bearing design groups after approximately 10 years; this finding is consistent with previous studies. However, the revision rates in the mobile-bearing group were lower than those in the fixed-bearing group, and our subgroup analysis showed that this tendency in the mobile-bearing group was much stronger in the posterior cruciatesubstituting subgroup than in the posterior cruciate- retaining subgroup. The trends for aseptic loosening, deep infection and osteolysis did not change regardless of whether the cruciate was retained. The heterogeneity for osteolysis was relatively large in both the original and subgroup analyses. The small sample size and insufficient follow-up duration may have caused these phenomena. Future studies are needed to acquire more data and confirm our results.

Other values in the included studies compared the benefits and harms of the two bearing designs. For example, B. G. Pijls et al. found that after approximately 10 years of follow-up, there was no significant difference in the femorotibial alignment angle, $\alpha$ angle (frontal angle of the femoral component), $\beta$ angle (frontal angle of the tibial component) and $\delta$ angle (sagittal angle of the tibial component) between the fixed-bearing and mobile-bearing groups [19]. N. Poirier et al. reported that 9 years after surgery, no clear difference was found in subjective patient satisfaction with the surgical outcome between the fixed-bearing and mobile-bearing groups [22],

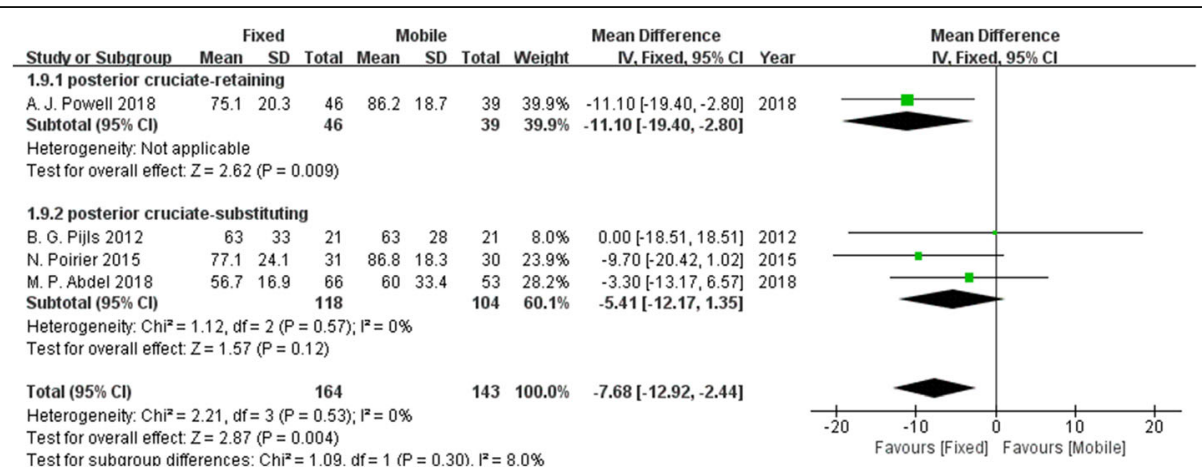

Fig. 8 The forest plot of the subgroup analysis of the KSFSs. Compared with the fixed bearing design group, the KSFSs was increased in the mobile-bearing design group with posterior cruciate retention, while there was no significant difference in the KSFSs between the two groups without posterior cruciate retention 


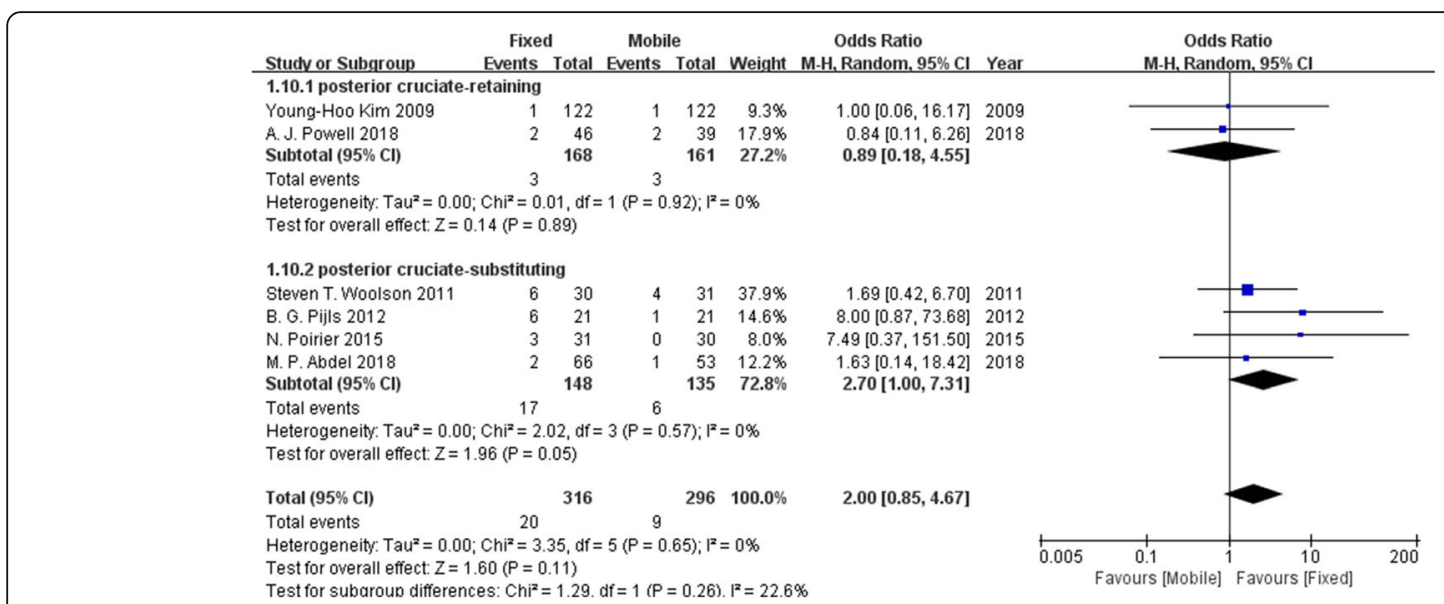

Fig. 9 The forest plot of the subgroup analysis of revision rates. There is no clear difference in the revision rates between the fixed-bearing and the mobile-bearing groups regardless of whether the posterior cruciate ligament was retained

while A. J. Powell et al. indicated that the mobilebearing group had a significantly higher score on the 12-Item Short-Form Health Survey and Knee Injury and Osteoarthritis Outcome Score assessment than the fixed-bearing group did [20]; however, we speculate that one possible reason may be that their TKA procedure retained the posterior cruciate ligament. In addition, these outcomes were reported in only one study and could not be included in our metaanalysis; further studies are required to explore these variables.

Mobile-bearing TKA was developed to reduce polyethylene contact stress by decreasing the increased wear associated with the fixed-bearing design, thus improving joint function and reducing the revision rates. However, these advantages used to be regarded as theoretical since several clinical trials suggested that the mobile-bearing design had no clear advantage over the fixed-bearing design [25, 26]. In addition, a recent meta-analysis concluded that there was no significant difference in radiostereographic migration rates between mobile-bearing and fixed-bearing implants [27], indicating that the revision rates between the two bearing designs may have no clear difference. Our meta-analysis further compared the benefits and harms between the two bearing designs over approximately 10 years of follow-up and the results showed that the mobilebearing design had advantages over the fixed-bearing design in KSFSs. The mobile-bearing design may also have advantages in the revision rates. Our study also suggests that posterior cruciate ligament retention may influence the effect of the two designs on KSKSs and revision rates. A previous study showed

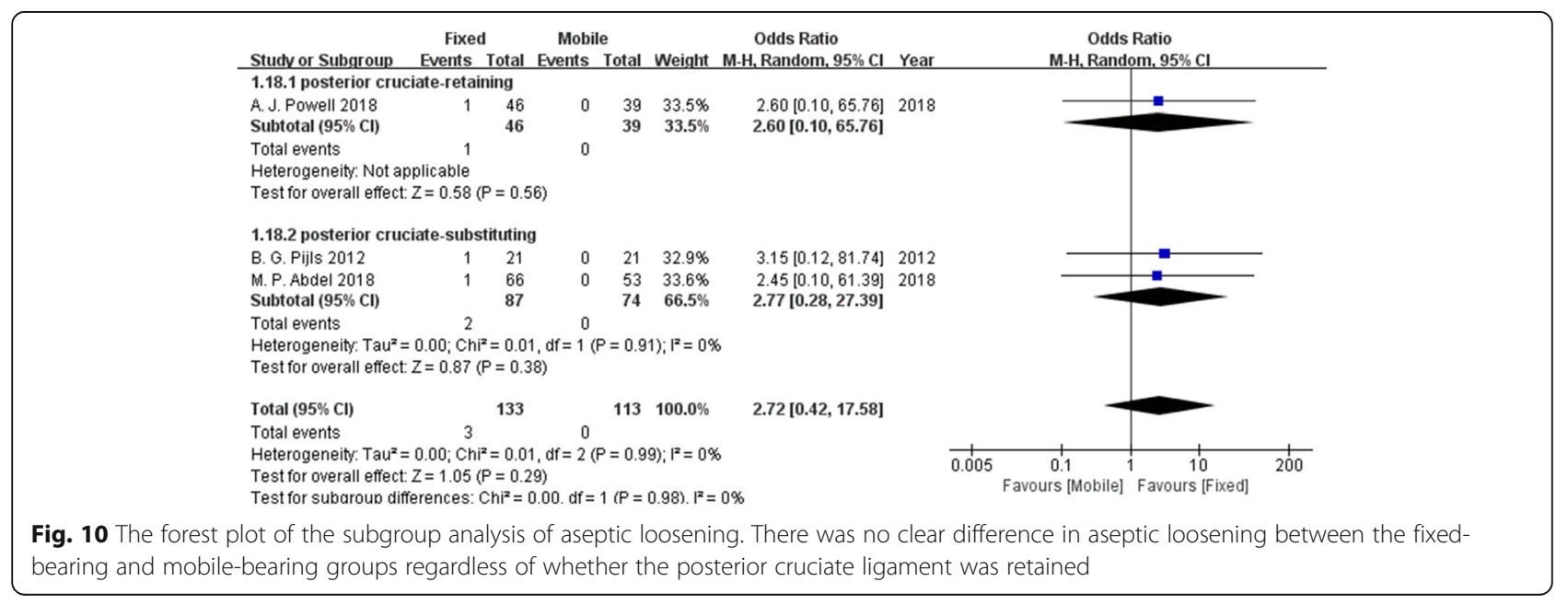




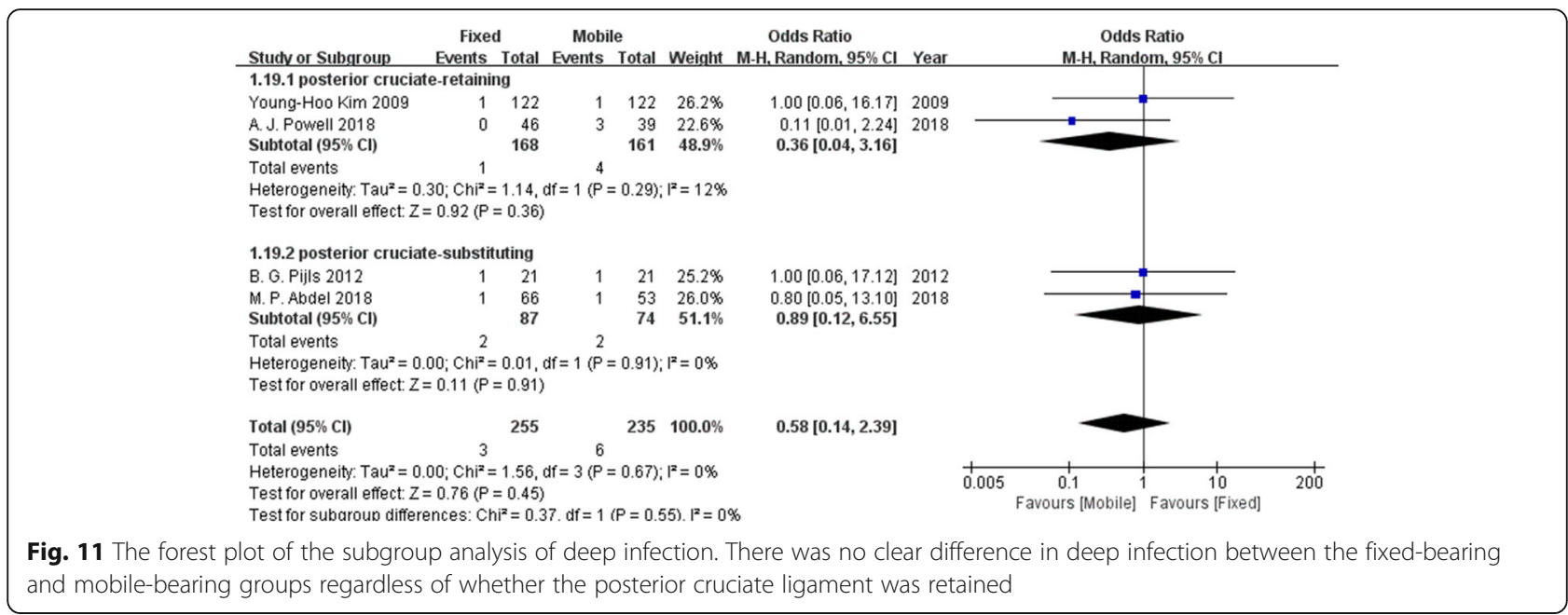

that KSSs and ROM differ between posterior cruciate ligament retention TKA and posterior cruciate ligament-substituting TKA [28]. Further studies are still needed to explore this field, acquire more data and update our results. In addition, approximately 10 years of follow-up may be insufficient considering the average implant lifespan, and longer trials should be implemented to obtain more long-term data.

Although the methodological quality of nearly all included studies was relatively high, there were some limitations of this meta-analysis. First, the number of included studies was relatively small, which may have affected the results of the forest plots. Additionally, due to the small sample size, we were not able to test for publication bias via funnel plots. Second, only two studies retained the posterior cruciate ligament, and only one of them reported knee function, which may have influenced our results. Third, one study used fixed- and mobile-bearing implants manufactured by different companies, which may have influenced our results. Finally, we analysed only articles published in English, which could have been a source of bias.

\section{Conclusion}

Our meta-analysis of RCTs showed that after approximately 10 years of follow-up, the mobile-bearing design has advantages in KSFSs over the fixed-bearing design. The mobile-bearing design may also have advantages in the revision rates over the fixed-bearing design when the posterior cruciate ligament is substituted. There may be no clear difference in KSKSs, ROM values or complication rates between these two designs. However, the small sample size may have influenced our results, and future studies with longer follow-up durations are needed to obtain additional data and more reliable results in this ambiguous field of research.

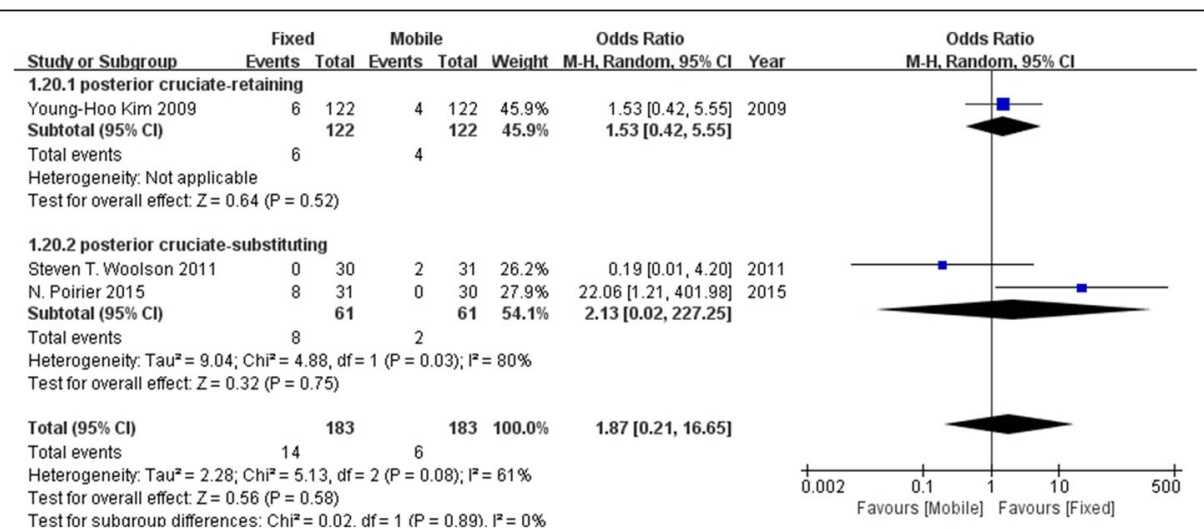

Fig. 12 The forest plot of the subgroup analysis of osteolysis. There was no clear difference in osteolysis between the fixed-bearing and mobilebearing groups regardless of whether the posterior cruciate ligament was retained 


\section{Abbreviations}

OA: Osteoarthritis; RA: Rheumatoid arthritis; TKA: Total knee arthroplasty; RCTs: Randomized controlled trials; KSSs: Knee Society Scores (KSSs); ROM: Range of motion; OR: Odds ratio; Cl: Confidence interval; SD: Standard deviation; IQR: Interquartile range; BMI: Body mass index; KSKSs: Knee Society Knee Scores; KSFSs: Knee Society Function Scores

\section{Acknowledgements}

None

\section{Authors' contributions}

Dongsheng Hao: designed the research, analysed the data, and wrote and checked the paper. Junjie Wang: performed the research, collected the data, and analysed the data. The authors read and approved the final manuscript.

\section{Funding}

None.

Availability of data and materials

As a meta-analysis, there are no patient data sets.

\section{Declarations}

\section{Ethics approval and consent to participate}

Not applicable

\section{Consent for publication}

Not applicable

\section{Competing interests}

The authors declare that they have no competing interests.

\section{Author details}

'Shanxi Bethune Hospital, Shanxi Academy of Medical Science, No. 99, Longcheng Street, Taiyuan 030032, Shanxi Province, China. ${ }^{2}$ Qingdao University, Qingdao, China.

Received: 28 April 2021 Accepted: 15 June 2021

Published online: 06 July 2021

\section{References}

1. Kurtz S, Ong K, Lau E, Mowat F, Halpern M. Projections of primary and revision hip and knee arthroplasty in the United States from 2005 to 2030. Bone Joint Surg Am. 2007;89(4):780-5

2. Pereira D, Peleteiro B, Araujo J, Branco J, Santos RA, et al. The effect of osteoarthritis definition on prevalence and incidence estimates: a systematic review. Osteoarthr Cartil. 2011;19(11):1270-85. https://doi.org/10.1016/j.joca.2 011.08.009.

3. Bozic KJ, Kurtz SM, Lau E, Ong K, Chiu V, Vail TP, et al. The epidemiology of revision total knee arthroplasty in the United States. Clin Orthop Relat Res. 2010:468(1):45-51. https://doi.org/10.1007/s11999-009-0945-0.

4. Chang MJ, Lim H, Lee NR, Moon YW. Diagnosis, causes and treatments of instability following total knee arthroplasty. Knee Surg Relat Res. 2014;26(2): 61-7. https://doi.org/10.5792/ksrr.2014.26.2.61.

5. Goodfellow J, O'Connor J. The mechanics of the knee and prosthesis design. J Bone Joint Surg (Br). 1978;60-b(3):358-69.

6. Gioe TJ, Sharma A, Tatman P, Mehle S. Do "premium" joint implants add value?: analysis of high cost joint implants in a community registry. Clin Orthop Relat Res. 2011;469(1):48-54. https://doi.org/10.1007/s11999010-1436-z

7. Callaghan JJ, Insall JN, Greenwald AS, Dennis DA, Komistek RD, Murray DW, et al. Mobile-bearing knee replacement: concepts and results. Instr Course Lect. 2001:50:431-49.

8. Collier JP, Mayor MB, McNamara JL, Surprenant VA, Jensen RE. Analysis of the failure of 122 polyethylene inserts from uncemented tibial knee components. Clin Orthop Relat Res. 1991;273:232-42.

9. Grupp TM, Kaddick C, Schwiesau J, Maas A, Stulberg SD. Fixed and mobile bearing total knee arthroplasty--influence on wear generation, corresponding wear areas, knee kinematics and particle composition. Clin Biomech. 2009;24(2):210-7.
10. Bistolfi A, Massazza G, Lee GC, Deledda D, Berchialla P, et al. Comparison of fixed and mobile-bearing total knee arthroplasty at a mean follow-up of 116 months. J Bone Joint Surg Am. 2013;95(12):e83.

11. McGonagle $\mathrm{L}$, Bethell $\mathrm{L}$, Byrne N. Bolton-Maggs BG The Rotaglide+ total knee replacement: a comparison of mobile versus fixed bearings. Knee Surg Sports Traumatol Arthrosc. 2014;22(7):1626-31. https://doi.org/10.1007/s001 67-012-2351-5.

12. Hofstede SN, Nouta KA, Jacobs W, van Hooff ML, Wymenga AB, et al. Mobile bearing vs fixed bearing prostheses for posterior cruciate retaining total knee arthroplasty for postoperative functional status in patients with osteoarthritis and rheumatoid arthritis. Cochrane Database Syst Rev. 2015:(2):Cd003130.

13. Lombardi AV Jr, Mallory TH, Fada RA, Hartman JF, Capps SG, Kefauver CA, et al. An algorithm for the posterior cruciate ligament in total knee arthroplasty. Clin Orthop Relat Res. 2001;392:75-87. https://doi.org/10.1097/ 00003086-200111000-00010.

14. Baldini A, Scuderi GR, Aglietti P, Chalnick D. Insall JN Flexion-extension gap changes during total knee arthroplasty: effect of posterior cruciate ligament and posterior osteophytes removal. J Knee Surg. 2004;17(2):69-72. https:// doi.org/10.1055/s-0030-1248201.

15. Shuster JJ. Review: Cochrane handbook for systematic reviews for interventions, Version 5.1.0, published 3/2011. Julian P.T. Higgins and Sally Green, Editors. Res Synth Methods. 2011;2(2):126-30. https://doi.org/10.1002/jrsm.38.

16. Insall JN, Dorr LD, Scott RD, Scott WN. Rationale of the Knee Society clinical rating system. Clin Orthop Relat Res. 1989:248:13-4.

17. Abdel MP, Tibbo ME, Stuart MJ, Trousdale RT, Hanssen AD, et al. A randomized controlled trial of fixed- versus mobile-bearing total knee arthroplasty: a followup at a mean of ten years. Bone Joint J. 2018;100-b(7):925-9.

18. Kim YH, Kim JS. Prevalence of osteolysis after simultaneous bilateral fixedand mobile-bearing total knee arthroplasties in young patients. J Arthroplast. 2009;24(6):932-40. https://doi.org/10.1016/j.arth.2008.05.005.

19. Pijls BG, Valstar ER, Kaptein BL, Nelissen RG. Differences in long-term fixation between mobile-bearing and fixed-bearing knee prostheses at ten to 12 years' follow-up: a single-blinded randomised controlled radiostereometric trial. J Bone Joint Surg (Br). 2012;94(10):1366-71.

20. Powell AJ, Crua E, Chong BC, Gordon R, McAuslan A, et al. A randomized prospective study comparing mobile-bearing against fixed-bearing PFC Sigma cruciate-retaining total knee arthroplasties with ten-year minimum follow-up. Bone Joint J. 2018;100-b(10):1336-44.

21. Woolson ST, Epstein NJ, Huddleston Jl. Long-term comparison of mobilebearing vs fixed-bearing total knee arthroplasty. J Arthroplast. 2011;26(8): 1219-23. https://doi.org/10.1016/j.arth.2011.01.014.

22. Poirier N, Graf P, Dubrana F. Mobile-bearing versus fixed-bearing total knee implants. Results of a series of 100 randomised cases after 9 years follow-up. Orthop Traumatol Surg Res. 2015;101(4 Suppl):S187-92. https://doi.org/10.1 016/j.otsr.2015.03.004.

23. Egger M, Davey Smith G, Schneider M, Minder C. Bias in meta-analysis detected by a simple, graphical test. Bmj. 1997;315(7109):629-34. https://doi. org/10.1136/bmj.315.7109.629.

24. Jiang C, Liu Z, Wang Y, Bian Y, Feng B, Weng X. Posterior cruciate ligament retention versus posterior stabilization for total knee arthroplasty: a metaanalysis. PLoS One. 2016;11(1):e0147865. https://doi.org/10.1371/journal. pone.0147865.

25. Van Hamersveld KT, Marang-Van De Mheen PJ, Van Der Heide HJL, Van Der Linden-Van Der Zwaag HMJ, Valstar ER, et al. Migration and clinical outcome of mobile-bearing versus fixed-bearing single-radius total knee arthroplasty. Acta Orthop. 2018:89(2):190-6. https://doi.org/10.1080/17453674.2018.1429108.

26. Feczko PZ, Jutten LM, van Steyn MJ, Deckers P, Emans PJ, Arts J. Comparison of fixed and mobile-bearing total knee arthroplasty in terms of patellofemoral pain and function: a prospective, randomised, controlled trial. BMC Musculoskelet Disord. 2017;18(1):279. https://doi.org/10.1186/s12 891-017-1635-9.

27. Pijls BG, Plevier JWM, Nelissen R. RSA migration of total knee replacements. Acta Orthop. 2018;89(3):320-8. https://doi.org/10.1080/17453674.2018.1443635.

28. Verra WC, van den Boom LG, Jacobs W, Clement DJ, Wymenga AA, et al. Retention versus sacrifice of the posterior cruciate ligament in total knee arthroplasty for treating osteoarthritis. Cochrane Database Syst Rev. 2013; 2013(10):Cd004803.

\section{Publisher's Note}

Springer Nature remains neutral with regard to jurisdictional claims in published maps and institutional affiliations. 